\title{
Continuidad y discontinuidad en la construcción de nicho: hacia una lectura política del proceso de domesticación*
} Continuity and Discontinuity in Niche Construction: Towards a Political Understanding of Domestication Process

\author{
Lev Jardón Barbolla ${ }^{\dagger}$ \\ Alonso Gutiérrez Navarro ${ }^{\ddagger}$
}

\begin{abstract}
Resumen
La variación en estado doméstico ha sido estudiada por la biología evolutiva desde el inicio del programa darwinista de investigación, destacando la selección artificial como parte del desarrollo del concepto de selección natural. Recientemente la teoría de construcción de nicho ha sido usada para analizar los procesos de domesticación que históricamente han formado parte de la vida social en los seres humanos. En este trabajo abordamos las implicaciones de la selección artificial como elemento en la línea de tensión dialéctica entre la sociedad y la naturaleza. Desde una perspectiva marxista analizamos los elementos de continuidad y discontinuidad que la reproducción de una "segunda naturaleza" introduce en el proceso de construcción de nicho, concentrándonos en la dimensión política (Echeverría 2001) como proceso emergente en la re-producción de una identidad social y cultural en las sociedades humanas. En este trabajo nos centramos en el caso de las plantas domesticadas.

La existencia de un telos o intencionalidad subyacente configuran rasgos distintivos de la construcción de nicho humano (Zeder 2009) y centralmente de la selección artificial. La reproducción de una segunda naturaleza se orienta por un telos que no tiene que ver solamente con la magnitud escalar de los recursos apropiados por los seres humanos, sino con la generación de valores de uso adecuados a una cierta forma de vida social que es recreada y puesta en juego: una dimensión política.
\end{abstract}

Palabras clave: selección artificial - construcción de nicho - domesticación - valor de uso - Marx - praxis

\begin{abstract}
The variation under domestication has been studied by evolutionary biology since the beginning of the Darwinist research programme, highlighting artificial selection as a part of the development of the concept of natural selection. Recently, niche construction theory has been used to analyze the process of domestication which has historically been part of social life for human beings. In the present work we make an approach to the implications of artificial selection as an element in the line of dialectical tension between nature and society. We analyze from a Marxist perspective the elements of continuity and discontinuity that the reproduction of a "second nature" introduces in the process of niche construction. We focus on the politic dimension of use value (Echeverría 2001) as an emerging process in the reproduction of a social and cultural identity in human societies. In this work we focus on domesticated plants.

The existence of a telos or subjacent intentionality configures distinctive features of human niche construction (Zeder 2009) and centrally of artificial selection. The reproduction of a second nature is directed by a telos which is not only nor necessarily related to the magnitude of resources appropriated by human beings, but also to the generation of use value adapted to a certain form of social life that is recreated and given place: a politic dimension.
\end{abstract}

Keywords: artificial selection - niche construction - domestication - use value - Marx - praxis

\footnotetext{
* Recibido: 4 Abril de 2016. Aceptado con revisiones: 5 Diciembre de 2016.

+ Centro de Investigaciones Interdisciplinarias en Ciencias y Humanidades, Programa de Investigación en Ciencia y Tecnología, Universidad Nacional Autónoma de México. Para contactar al autor, por favor, escribir a: levjardon@ciencias.unam.mx.

* Facultad de Ciencias, Universidad Nacional Autónoma de México. Para contactar al autor, por favor, escribir a: alonsogn87@gmail.com.

$\$$ Agradecemos a los compañeros del Seminario Interdisciplinario sobre Domesticación y Agroecología del CEIICH. A los compañeros del Taller "Teoría de la Evolución, ideología y reduccionismo: un enfoque dialéctico". A Mariana Benítez, Luis Eguiarte, Kristin Mercer, Rodolfo Oliveros y Diego Méndez por las fructíferas discusiones en torno a este tema. A Emily Schultz, con quien discutimos algunas de las figuras aquí presentadas, y a Julia Moreno Mijares, que hizo una lectura crítica del manuscrito. Este trabajo contó con el apoyo de los proyectos PAPIIT (DGAPA-UNAM) IA202515 e IN400416. Los comentarios de los editores y de un dictaminador anónimo fueron de mucha utilidad para mejorar este artículo.

Metatheoria 8(2)(2018): 125-134. ISSN 1853-2322.

(c) Editorial de la Universidad Nacional de Tres de Febrero. Publicado en la República Argentina.
} 
El trabajo es, en primer lugar un proceso entre el hombre y la naturaleza, un proceso en el que el que el hombre media, regula y controla su metabolismo con la naturaleza. El hombre se enfrenta a la materia natural misma como un poder natural. Pone en movimiento las fuerzas naturales que pertenecen a su corporeidad, brazos y piernas, cabeza y manos, a fin de apoderarse de los materiales de la naturaleza bajo una forma útil para el movimiento de su propia vida. A operar por medio de este movimiento sobre la naturaleza exterior a él y transformarla, transforma a la vez su propia naturaleza.

Karl Marx ([1867] 2005, p. 215)

\section{Introducción: domesticación, selección y adaptación}

La domesticación como proceso y su resultado más evidente, la variación en estado doméstico, han sido estudiadas desde una perspectiva evolutiva desde hace más de 150 años, es decir tanto por el programa de investigación anterior a la síntesis moderna, como por la propia síntesis e incluso en el marco de una posible sintesis extendida (Darwin [1859] 2004, [1859] 2012, Vavilov 1926, Haldane 1924 1930, Harlan 1971, Gepts 2004, Odling-Smee et al. 2003, Kendall 2011, O’Brien \& Laland 2012).

Darwin ([1859] 2004, [1859] 2012) utilizó esta variación en estado doméstico, para construir por analogía el argumento de la selección natural como proceso generador de diversidad a partir de ancestros comunes. Al desarrollar su teoría, Darwin modifica las visiones que los naturalistas previos tenían sobre la naturaleza al escindir al organismo del ambiente y separar las causas de la variación en las especies de aquellas causas ambientales que originan las presiones de selección natural (Lewontin 2000). De esta manera los organismos son considerados objetos del proceso evolutivo, a diferencia de las teorías transformacionales (como el lamarckismo) en las que eran sujetos del cambio (Levins \& Lewontin 1985, Lewontin 2000). Esta separación sujeto-objeto se manifiesta también en el contexto de la llamada selección por el hombre (Darwin solo utiliza el término selección artificial una vez en el Origen de las Especies) en el sentido de que la adaptación de las plantas y animales domesticados ocurre en función de un ambiente externo y reconoce como sujetos del proceso de selección consciente a los cultivadores y mejoradores surgidos de la propia capitalización del campo en la Inglaterra Victoriana.

La distinción darwiniana entre selección consciente y selección inconsciente deriva en la persistente consideración de que existirían dos tipos de selección artificial. Por una parte, existiría selección inconsciente, llevada a cabo de manera no intencional, mediada por el hecho de que las plantas en cuestión han sido movidas de sus hábitats originales y colocadas en ambientes diferentes (y frecuentemente nuevos) manejados por los seres humanos; esta forma de selección sería apenas distinguible. Por otra parte, la selección consciente sería la aplicada deliberadamente por los cultivadores, buscando rasgos específicos de interés para ellos, la cual correspondería a la selección artificial propiamente dicha (Zohary 2004, Greggory 2009, Millá et al. 2015).

Darwin al construir el argumento por analogía, desarrolla una diferencia irreconciliable entre el proceso de selección artificial y selección natural. Los seres humanos (el hombre en el texto de Darwin), o al menos los criadores y fito-mejoradores que ubica como sujetos de la selección artificial, orientan el proceso selectivo. En la selección artificial existe un proceso teleológico (orientado a fines) en la domesticación, que Darwin reconoce, pero este proceso se reduce a un uso conscientemente utilitario, como son los ejemplos usados de los mejoradores, criadores o hibridólogos. Es decir, Darwin no lleva hasta sus últimas consecuencias este proceso. En la explicación de selección natural el ambiente aparece como el sujeto de la evolución y al construir de manera análoga la explicación de la selección artificial, el ser humano se convierte en sujeto de la evolución en la domesticación, pero como simple mediación del ambiente, seleccionando las plantas o animales que ofrecen mejores rendimientos en un contexto ambiental determinado. Desde esta perspectiva, no se considera al humano o al organismo como sujeto, mucho menos como sujeto social del proceso de cambio, sino como un agente encargado de exacerbar el proceso de adaptación a ambientes locales. El ambiente oscila así entre ser el medio contra el cual se contrasta a cada planta cultivada proceso de mejorar los rendimientos y el ser el sujeto causal del proceso evolutivo. 
Al mismo tiempo y de manera más sutil, la visión adaptacionista permeó en la concepción de cuáles son los llamados rasgos de interés, esto es cuál es el propósito que subyace a la selección artificial como eje del proceso de domesticación. Así, algunas interpretaciones surgidas desde la biología (Richerson et al. 2001, Murphy 2007) plantean las sociedades humanas habrían sido forzadas a adoptar la agricultura como una respuesta adaptativa (en el sentido de la selección natural) al cambio climático de hace aproximadamente 10,000 años denominado Dryas reciente. Este cambio implicó una relativa sequía y escasez de algunas de las plantas que eran base importante de las sociedades cazadorasrecolectoras en Medio Oriente.

El adaptacionismo implica una concepción particular del papel de los procesos selectivos en la domesticación y diversificación. En tanto que se supone que el objetivo o fuerza motriz fundamental de las sociedades humanas es solamente incrementar la cantidad de alimentos disponibles, se supone que el grueso de las presiones selectivas estaría orientado a incrementar los rendimientos por unidad de área, de modo que los seres humanos aparecen solamente como mediadores de la selección ejercida en función del ambiente (selección natural). Este discurso, se proyecta sobre algunos estudios de los procesos de domesticación (v.gr. Murphy 2007), y se refuerzan debido a que la agronomía dominante en occidente se ha propuesto como objetivo central el incremento en la magnitud escalar de las cosechas (Cardwell 1982, Gur \& Zamir 2004, Murphy 2007, Shomoura et al. 2008, Tester \& Langridge 2010).

Este trabajo se propone explorar cómo la teoría de construcción de nicho, y en particular la teoría de construcción de nicho humana puede entrelazarse con una concepción marxista de la actividad humana como praxis productiva (Sánchez Vázquez 2003). Esto con el objetivo de trascender el adaptacionismo como discurso dominante en el estudio de la domesticación de cultivos y al mismo tiempo poder comprender la dimensión política del valor de uso como una propiedad emergente de la producción material por los seres humanos, propiedad emergente que articula, a través del trabajo, el proceso de domesticación.

\section{El organismo como sujeto y objeto de la evolución: la construcción de nicho}

La separación sujeto-objeto como separación organismo-ambiente efectuada por Darwin ha sido reconocida por Levins y Lewontin (1985) y por el propio Lewontin (2000) como un paso históricamente necesario y trascendental para la biología, pero al mismo tiempo han planteado la necesidad de superar esa separación en aras de comprender al organismo y al ambiente como resultados de una interacción. Así, Levins y Lewontin llamaron a recuperar la noción de que organismo y ambiente están interpenetrados, ninguno de los dos polos de la interacción existe efectivamente sin el otro. Esto quiere decir que el organismo integra los aspectos o variables del medio que realmente relevantes para su vida y, al mismo tiempo, que la acción de los organismos modifica efectivamente el medio en el que se desenvuelven. Es decir, el organismo es sujeto y objeto de la evolución.

A partir del planteamiento de estos autores, pero centralmente del trabajo Triple Helix: Gene, Organism and Environment de Lewontin (2000), Odling-Smee et al. (2003) plantearon a la construcción de nicho como una dimensión emergente y como una vía de herencia adicional, a través de la cual los organismos de una generación afectan el ambiente en el que se desarrollan generaciones posteriores.

La dimensión de la construcción del nicho obliga a repensar la interacción organismo-ambiente trascendiendo su dimensión puramente ecológica para considerar ahora los efectos evolutivos de dicha interacción. Los autores de la teoría de construcción de nicho han puesto énfasis en señalar que la acción de los organismos sobre el medio modifica activamente las condiciones de selección que enfrentan las generaciones posteriores. Es allí donde la forma que ha tomado la teoría de construcción de nicho tiene su mayor limitación, incluso desde la genética de poblaciones más clásica tendría que reconocerse que existen otras vías de interacción entra el ambiente y la poza génica, centralmente el flujo como función de un ambiente permeable o no a la migración efectiva. 
Pero en la base de la teoría de construcción de nicho, al menos en la forma en que la concibió Lewontin este proceso, está el hecho de que la interacción organismo-ambiente, sea ontogenética o transgeneracional no existe por fuera de los seres vivos, sino que es constitutiva de la existencia misma de cada organismo, es decir el organismo existe en tanto que interactúa y la interacción existe en tanto que existe el organismo. El nicho tendría que ser entendido como resultado de una interacción en la que la vida de los organismos implica en sí misma la modificación a varios niveles de los factores bióticos y abióticos y al mismo tiempo estas modificaciones correspondientemente determinan la respuesta de los organismos (Leibold 1995, Leibold \& Geddes 2005). Esta interacción recíproca supera positivamente la falsa dicotomía entre causa y efecto del organismo y el ambiente (Lewontin 1978). Lo que existe es pues, una relación metabólica entre el organismo y el ambiente, en la que ambos polos de la oposición solamente pueden venir a ser juntos. Si esto es así para los organismos vivos en general, quedaría pendiente explorar la forma en la que el animal humano construye su nicho y el papel que puedan desempeñar las formas particulares en que esta construcción ocurre.

\subsection{Construcción de nicho humana y domesticación}

Desde la propia publicación de Niche Construction: The Neglected Process in Evolution (2003) sus autores exploraron los alcances de esta teoría para el estudio de la construcción de nicho humana (CNH), entendida esta como la capacidad de los seres humanos de modificar a escala masiva el ambiente en el que se desarrollan las sociedades de generación en generación. Así, esta teoría abrió en principio una forma superar desde la biología las explicaciones deterministas biológicas que adscribían primacía ontológica a los genes sobre la cultura (Dawkins 1982). Pero al mismo tiempo, la perspectiva de la $\mathrm{CNH}$ ha pretendido abarcar de diferentes maneras dentro de su campo explicativo a la cultura o al menos incluir a la herencia cultural como parte de las vías de herencia adicionales a la genética (Figura 1).

Figura 1

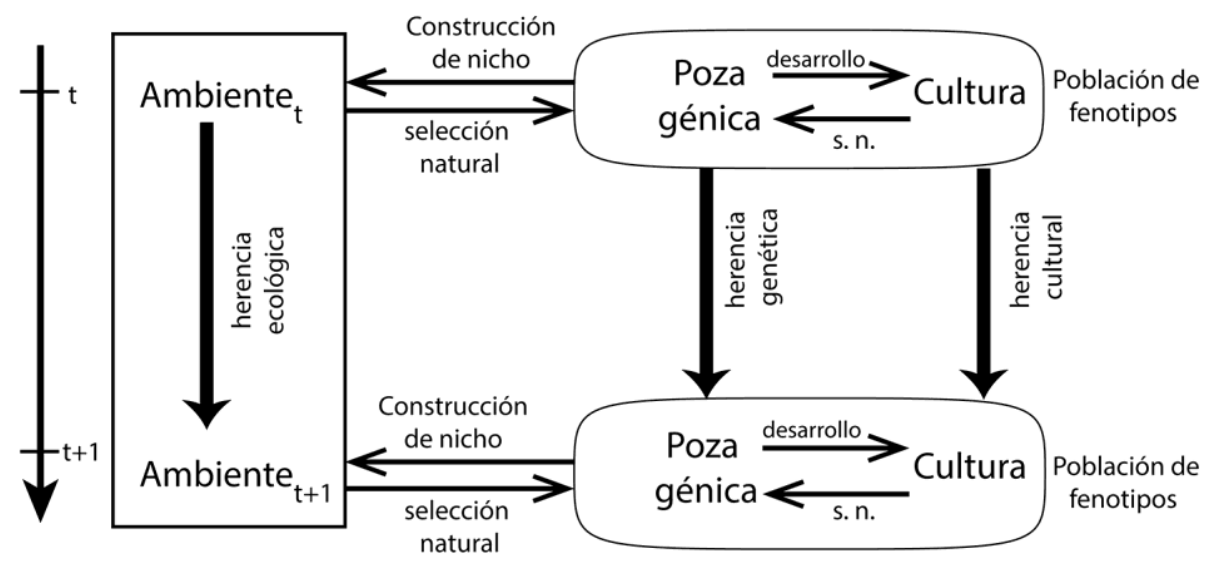

Tres vías de herencia propuestas para la construcción de nicho humano (CNH). A diferencia de la construcción de nicho común al resto de los organismos, los seres humanos presentan una vía de herencia cultural (adaptado de Schultz 2015).

El tema de la domesticación ha sido abordado desde la teoría de la construcción del nicho resaltando como hecho novedoso la magnitud espacial de la construcción (Smith 2007, 2011, Schultz 2015), así como en el escalamiento en la capacidad de construcción de nicho (Smith 2007). También se ha señalado a la domesticación como un proceso que sirve de retroalimentación a la evolución humana por el uso de artefactos (O’Brien \& Laland 2012) y en el caso más extremo se ha planteado que la herencia cultural estaría contenida, como un caso particular de la herencia ecológica derivada de la construcción del nicho humana (Kendal 2011). 
Más allá de discutir cada una de estas aproximaciones, centramos el análisis en preguntarnos sobre la distinción entre la construcción del nicho humana y la de otros organismos. Hemos encontrado diferentes respuestas como la amplitud de su impacto (Smith 2007), la existencia de un telos (Zeder 2009), la velocidad de adaptación gen-cultura (O’Brien \& Laland 2012) o que la herencia cultural está incluida en la ecológica y por lo tanto no habría diferencia. Nosotros pensamos que el nicho humano es el espacio-tiempo donde se da ese proceso conjunto que abarca tanto los procesos de evolución biológica (que contiene, pero no se limita a la selección natural por el medio circundante) y de construcción de una identidad social en constante cambio, mediada por elecciones colectivas e individuales. A partir de esto exploraremos en qué podría consistir esa diferencia cualitativa entre la actividad de los organismos (construcción de nicho en general) y la del humano (construcción de nicho y praxis). La domesticación, para nosotros, debería estudiarse considerándola en el marco de una relación metabólica mediada por la socialidad (Echeverría 1998).

El pensamiento crítico marxista reconoce a los seres humanos como parte de la naturaleza, de la cual al mismo tiempo dependen para la satisfacción de sus necesidades en sentido amplio, y ubica a la relación sociedad-naturaleza como socialmente determinada. A partir de lo anterior, los resultados de las investigaciones surgidas del marxismo para analizar la actividad humana pueden ser de utilidad para comprender qué es lo que los seres humanos producen cuando construyen su nicho. La cuestión aquí es, si dicha construcción de nicho humana $(\mathrm{CNH})$, teniendo una base material compartida con la construcción de nicho en general, es reductible a la re-producción biológica o si, por el contario, existen nuevas dimensiones poieticas, creativas, que sería relevante tratar como propiedades emergentes de la producción material de la vida humana, producción necesariamente social. No podemos perder de vista que la domesticación ocurre como parte de esta producción material de la vida humana.

\section{Continuidad y discontinuidad en la domesticación: la producción de valores de uso}

En tanto que acción recíproca del organismo sobre el medio, ciertamente los procesos agrícolas y en particular los procesos de domesticación son procesos que surgen de la capacidad biológica de construir el nicho. Sin embargo, la interacción de los seres humanos con dicho medio aparece mediada por una forma particular de actividad, la actividad específicamente humana o praxis $^{1}$ y dentro de ésta la praxis productiva (Sánchez Vázquez 2003), que se ha manifestado hasta hoy como trabajo humano:

La praxis productiva es así la praxis fundamental porque en ella el hombre no sólo produce un mundo humano o humanizado, en el sentido de un mundo de objetos que satisfacen necesidades humanas y que sólo pueden ser producidos en la medida en que se plasman en ellos fines o proyectos humanos, sino también en el sentido de que en la praxis productiva el hombre se produce, forma o transforma a sí mismo. (Sánchez Vázquez 2003, p. 274)

La forma de trabajo o de praxis productiva es el proceso fundamental por el que la humanidad "media, regula y controla su metabolismo con la naturaleza" (Marx 2005[1867]), es el fenómeno emergente fundamental en la actividad agrícola (mediante la cual se construye el nicho humano), fenómeno que regula la mutua determinación de diferentes niveles de interacción que existen dentro del sistema agrícola: las poblaciones individuales de plantas en proceso de domesticación.

Más aún, justamente a partir de la revolución neolítica se exacerba la capacidad del trabajo humano para producir un excedente, es decir, para producir por encima de las necesidades inmediatas. Esta propiedad emergente tiene implicaciones inmediatas para el proceso de construcción de nicho humano, pues hace que la interacción sociedad-naturaleza de la cual emerge la formación cultura en

\footnotetext{
1 Para Sánchez Vázquez, la distinción entre la actividad en general y la actividad específicamente humana es central en tanto que en ésta última "entraña la intervención de la conciencia gracias a la cual el resultado existe dos veces -y en tiempos distintos-: como resultado ideal y como producto real” (Sánchez Vázquez 2003, p. 264). Por nuestra parte, tratamos de trazar un paralelismo con esta distinción para abordar la construcción de nicho específicamente humana.
} 
general no pueda ya ser conceptualizada como simple interacción mediada por la selección natural desde el medio hacia los seres humanos y modificación simple o general del medio por la actividad humana como si esta fuese solamente actividad biológica.

La mediación a través la cual los seres humanos se apropian de la naturaleza, es decir, producen, es la praxis productiva, que hemos conocido bajo la forma de trabajo. Esta actividad específicamente humana, esta capacidad de producir un excedente viene a ser al mismo tiempo que la capacidad del ser humano de dotarse de una cierta forma social. Esta forma social no es parte de lo ya dado por el sistema genético, sino que es producto de la forma concreta de esa socialidad que es puesta en juego constantemente (Echeverría 2001).

Fundada en esa capacidad de producir por encima de la necesidad, Bolívar Echeverría (1998) señala que aparece también una especie hybris o desmesura en la existencia del ser humano. Esta desmesura estribaría en que el ser humano o ser animal gregario al producir objetos útiles (valores de uso), no solo produce los objetos que satisfacen una necesidad en abstracto, sino una necesidad socialmente determinada.

En el caso de la selección artificial se abre entonces la cuestión de hasta qué punto se ha tratado de un proceso guiado con el fin de solamente adaptar las plantas cultivadas al medio de cultivo en aras de maximizar la magnitud de las cosechas. En la producción agrícola, como en toda producción, los seres humanos intervienen a través del trabajo sobre medios y objetos de trabajo provistos directa o indirectamente por la naturaleza, modificándola, dando lugar a una "nueva realidad que subsiste independientemente del sujeto o sujetos que la engendraron con su actividad subjetiva" (Sánchez Vázquez 2003, p. 71), es decir, construyen su nicho. Hay pues, un paralelismo, pero es imposible soslayar que existe una dimensión nueva en la actividad humana: la actividad teleológica, orientada a fines, acordes a la re-producción de una determinada identidad social. La adecuación a esta identidad social determina, nos dice Bolívar Echeverría, incluso la aceptación o no de los valores de uso producidos y de los alimentos en particular está mediada por la adecuación o no a los fines que el sujeto social (la comunidad en otro tiempo, el mercado como sujeto social sustitutivo en el capitalismo) se ha planteado en el propio proceso productivo (en el cual se inserta la selección artificial). Ésta es pues la base de lo que se conoce como dimensión política del valor de uso, la capacidad de las sociedades humanas de inclusive codificar mensajes en el proceso productivo mismo:

El alimento del animal es perceptible para él como más o menos apto para llenar una determinada
carencia del mismo; el alimento humano, en cambio, es perceptible no sólo como capaz de satisfacer un
determinado tipo de hambre, sino también, y sobre todo, como más o menos sabroso y como
diferentemente sabroso. El sabor o la forma gustativa del alimento humano no es una forma puramente
natural sino una forma "social natural". Por ello es capaz de cambiar de configuración no sólo de una
situación histórico-concreta a otra sino incluso de un episodio de producción/disfrute a otro.
(Echeverría 2001, pp. 73-74)

La discontinuidad en la continuidad emerge porque al ejercer la selección artificial el sujeto social (que puede no ser un fitomejorador parte del aparato científico-técnico) los sujetos de la praxis productiva eligen no solamente las plantas que crecen mejor en un ambiente determinado, sino que eligen ante todo, las plantas que se adecuan mejor a un cierto aparato de necesidades y capacidades productivas, a un cierto modo general de re-producir la vida humana a cierta forma cultural en construcción (por ejemplo la de una comunidad campesina). En el capitalismo, la forma concreta que toma esa socialidad es la que hace de su telos o fin fundamental la de la maximización de una dimensión escalar: la producción de valor; la masa de cosecha aparece entonces como covariable de la masa total de excedente social a ser apropiado por una clase social específica. Sin embargo, este hecho es en sí mismo un producto histórico, y no debería ser el lente bajo el cual se mira el proceso de domesticación como un todo, proyectándose hacia el pasado como tabula rasa.

La selección natural y la selección artificial, bajo esta discusión, serían entonces campos involucrados en el proceso de formación de la "segunda naturaleza" o la transnaturalización propia de los seres humanos. Interesan por cuanto participan en la conformación de los instrumentos de 
producción y en particular de las semillas y el suelo como instrumentos y objetos de trabajo. La "segunda naturaleza" a la que hacemos mención consiste en que cada ciclo de reproducción de la vida social es puesto en juego la propia estructura social, sin esperar a que se dé el tránsito de una generación a otra. Por eso es posible hablar de lo político como característica propiamente humana y también por ello la cultura no puede ser reducida a una serie cuantos o comportamientos individuales, sino antes bien ser entendida como parte de un proceso.

Figura 2

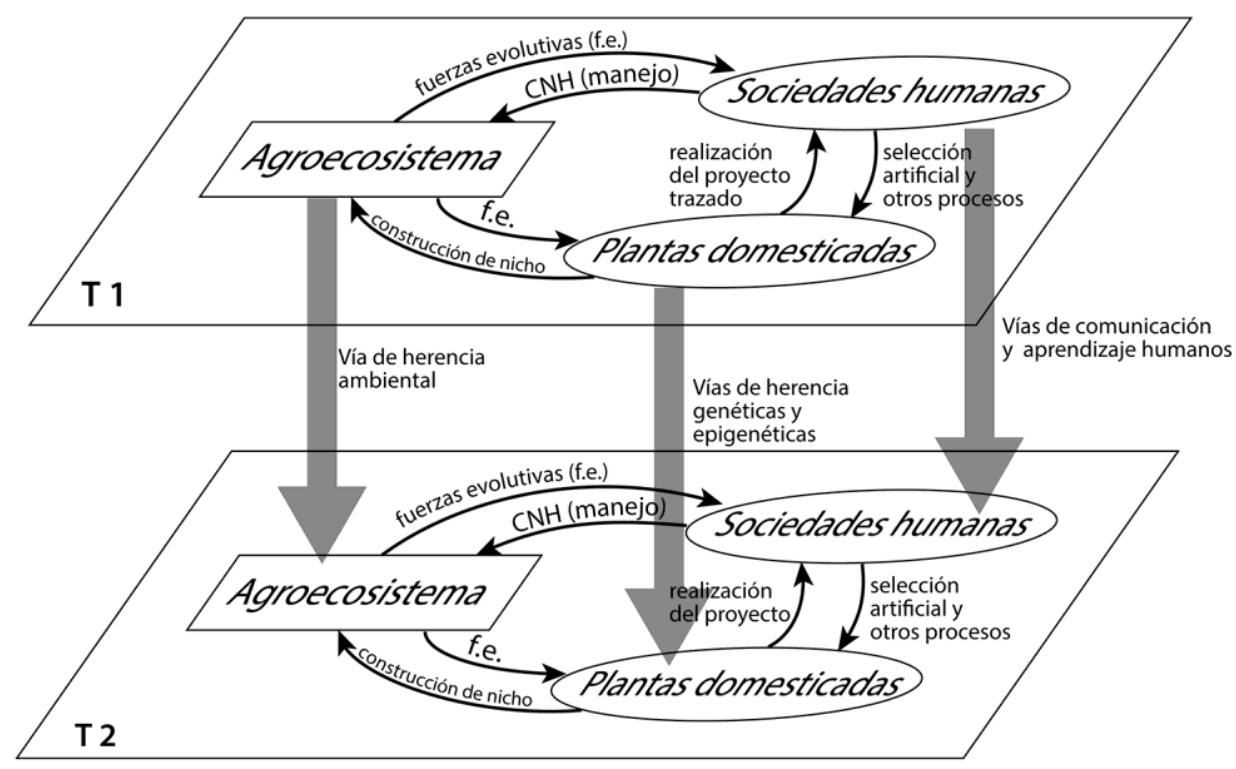

Tres polos de interacción en la formación de la agrobiodiversidad. Los grupos humanos, organizados socialmente actúan al mismo tiempo sobre el medio circundante y sobre poblaciones de plantas domesticadas específicas. Distintas fuerzas evolutivas f.e. (incluyendo, pero no limitándose a la selección natural) son la mediación activa de la acción del ambiente sobre las sociedades humanas. Las Sociedades humanas manejan el agroecosistema, lo cual es una manifestación concreta de la construcción de nicho humana $(\mathrm{CNH})$, a través de las diferentes prácticas agrícolas y su impacto a nivel incluso paisajístico. Al mismo tiempo, las plantas domesticadas, como producto de su actividad biológica (actividad en general) modifican el ambiente (agroecosistema) al consumir nutrientes del suelo y dejar productos de desecho, modificando la composición del mismo, al alterar la incidencia de la luz a la superficie, la humedad relativa, etc.; es decir, construyen su nicho en el sentido de Odling-Smee et al. (2003). Los tres polos de la interacción se determinan mutuamente y en los tres existe un nivel en el que lo acontecido en un momento $\left(T_{1}\right)$ determina -así sea parcialmente- las posibilidades del futuro $\left(T_{2}\right)$ a través de diferentes vías de herencia, pero sólo en el polo de las sociedades humanas aparece la posibilidad de que la actividad del presente $\left(T_{1}\right)$ se halle condicionada por el futuro $\left(T_{2}\right)$ o lo que se espera de él, praxis. Las flechas que fluyen desde las sociedades humanas hacia los niveles agroecosistémico y poblacional son flechas peculiares, diferentes al ser relaciones mediadas por la praxis productiva o trabajo.

\section{Hacia una lectura política del proceso de domesticación}

La selección artificial realizada por los campesinos no sería entonces sólo una búsqueda por incrementar la cosecha sino parte de la reproducción-recreación de una cierta identidad social y cultural, particularmente entre los pueblos indígenas. Esto es un proceso político en el que los humanos no solamente reproducen su existencia como seres sociales, inacabados, y su identidad como sujetos colectivos.

La domesticación como una relación material y semiótica incide no solamente sobre las formas particulares de las plantas que se cultivan, sino que es al mismo tiempo parte del proceso de 
humanización y reproducción de la vida social. Así, ambos polos de la interacción se encuentran interpenetrados, en mutua determinación.

Figura 3

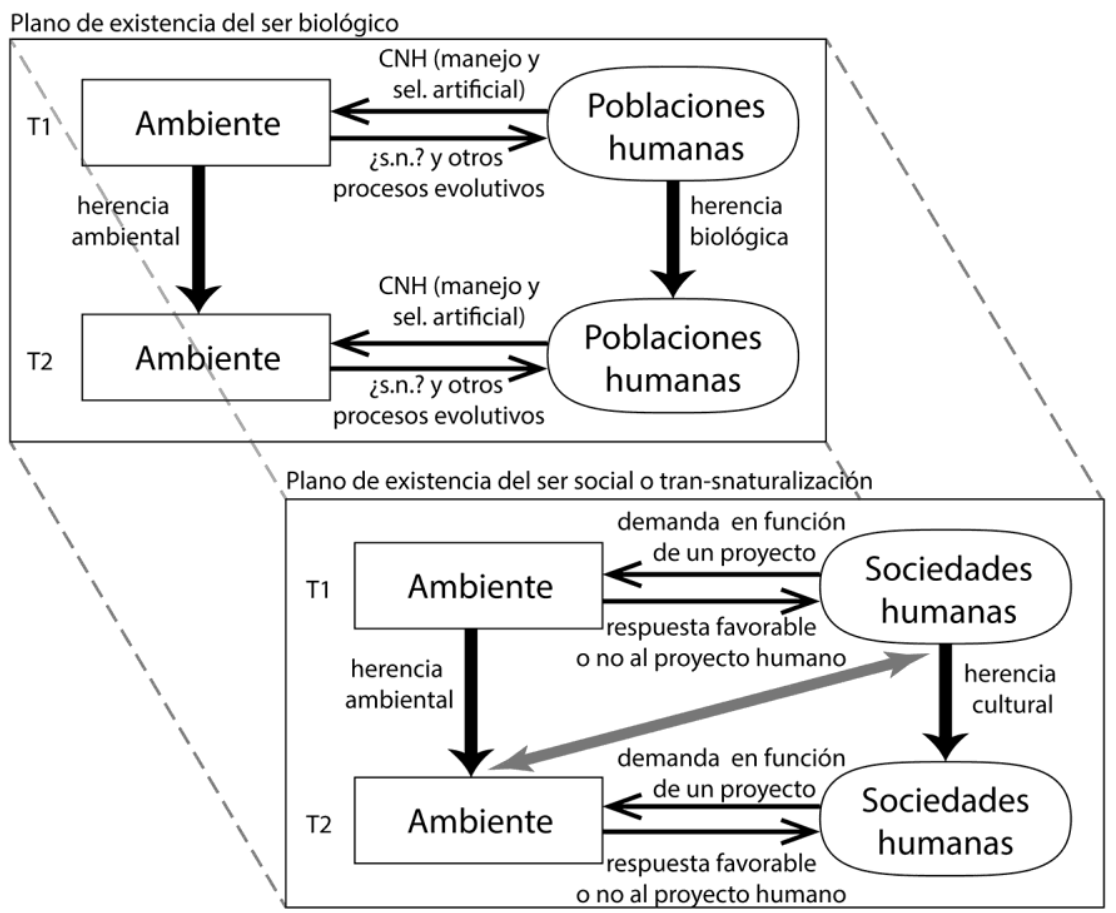

Dos planos de existencia del ser humano. La interacción humano naturaleza a través del proceso productivo encierra dos procesos que ocurren en forma paralela. Por una parte, el plano en el que los seres humanos interactúan con su medio construyendo el nicho humano y se enfrentan a ese resultado de su relación metabólica de forma análoga a como lo hacen otros seres biológicos. En el plano de reproducción de la vida social parece una propiedad emergente: los seres humanos actúan sobre el medio en función de un proyecto, de una prefiguración de los resultados esperados de su actividad, esta prefiguración se representa con una flecha diagonal que conecta el futuro con el presente.

Esto permite postular la existencia de elementos de continuidad con la construcción de nicho en general, pues la propia mutua determinación organismo-ambiente es la base biológica desde la cual se abren las posibilidades de existencia humanas. Pero al mismo tiempo, aparece un elemento de discontinuidad en la reproducción en paralelo de otro plano de existencia, también basado en la interacción material sociedad-naturaleza (Figura 3).

La acción de los seres humanos sobre la naturaleza como actividad práctica conlleva y hace posible la existencia ambos planos de reproducción de la vida, el biológico y social, los cuales se ponen en juego en el mismo proceso material. Así, estos dos planos de existencia se encuentran mutuamente determinados $\mathrm{y}$, en forma paralela en ambos planos se da una interacción espacio-temporal entre los seres humanos y el ambiente. Producto de esa interacción los seres humanos construyen su nicho, pero al mismo tiempo ponen en juego su propia identidad en tanto grupos humanos, es decir producen cultura (en el sentido de Echeverría 1998).

Existen rasgos que distinguen cualitativamente el proceso de construcción de nicho humano, tales que es posible hablar de una dimensión política del proceso de domesticación. Esta dimensión política orientaría los procesos de construcción de nicho humano, particularmente los procesos de selección artificial. De esta manera, las condiciones y objetivos (telos) impuestos sobre la reproducción social de la vida humana tendrían una incidencia sobre las manifestaciones o impactos del proceso de construcción de nicho humano en los diferentes niveles de organización de la materia viva (genes, 
fenotipos, especies, comunidades agroecosistémicas). En tanto que el trabajo o praxis productiva aparece como propiedad emergente en la relación metabólica sociedad-naturaleza, la re-producción cultural propia de los seres humanos trasciende el campo de la construcción de nicho en general y abre formas de interpenetración sujeto-objeto cualitativamente diferentes.

De aquí se desprende que la forma que toma el trabajo como mediación metabólica entre a sociedad y la naturaleza son indispensables para la comprensión del proceso de domesticación. Ésta no puede ser vista como simple construcción de nicho, sino que debe abordarse considerando el papel que ésta ha jugado en la construcción de diferentes identidades culturales y relaciones sociales, es decir, en un proceso político en el que los seres humanos como sujetos de la domesticación, se han transformado a sí mismos

La presente investigación abre un panorama en el cual se esbozan derroteros teóricos y prácticos. Nos permite plantear la hipótesis en construcción: que la diversidad de los cultivos y la permanencia de dicha diversidad estarían determinadas, al menos parcialmente por la llamada dimensión política del valor de uso (Echeverría 2001), expresada en los criterios de selección artificial y los modos de manejo agrícola. Esto se podría corroborar en los patrones de variación biológica a diferentes niveles (p.e. genético, fenotípico) y a partir de lo anterior podemos construir un sistema de hipótesis particulares susceptibles de ser probadas a partir de datos obtenidos en campo y del trabajo con la gente.

Bibliografía

Cardwell, V. (1982), "Fifity Years of Minnesota Corn Production: Sources of Yield Increase”, Agronomy Journal 74: 984 989.

Darwin, C. ([1859] 2004), On the Origin of Species, Cambridge: Harvard University Press.

Darwin, C. ([1868] 2012), The Variation of Animals and Plants Under Domestication, London: Forgotten Books-Classic Reprints.

Dawkins, R. (1982), The Extended Phenotype: The Gene as the Unit of Selection, Oxford: Oxford University Press.

Echeverría, B. (1998), Valor de uso y utopía, México: Siglo XXI.

Echeverría, B. (2001), Definición de la cultura, México: Facultad de Filosofía y Letras, UNAM-Itaca.

Gepts, P. (2004), "Domestication as a Long Term Selection Experiment”, Plant Breeding Reviews 24: 1-44.

Greggory, T.R. (2009), “Artificial Selection and Domestication: Modern Lessons from Darwin's Enduring Analogy”, Evolution, Education and Outreach 2: 5-27.

Gur, A. y D. Zamir (2004), "Unused Variation Can Lift Yield Barriers in Plant Breeding”, PLoS Biology 2: e204.

Haldane, J.B.S. (1924-1934), "A Mathematical Theory of Natural and Artificial Selection Parts I-X”, Transactions of the Cambridge Philosophical Society.

Haldane, J.B.S. (1934), "A Mathematical Theory of Natural and Artificial Selection. Part X. Some Theorems in Artificial Selection”, Genetics 19: 412-429.

Harlan, J.R. (1971), “Agriculture Origins: Centers and Non-Centers”, Science 174: 468-474.

Kendal, J., Tehrani, J. y J. Odling-Smee (2011), "Human Niche Construction in Interdisciplinary Focus", Philosophical Transactions of the Royal Society, Series B 366: 785-792.

Leibold, M.A. (1995), "The Niche Concept Revisited: Mechanistic Models and Community Context", Ecology 76: 1371-1382.

Leibold, M.A. y P. Geddes (2005), "El concepto de nicho en las metacomunidades”, Ecología Austral 15: 117-129.

Levins, R. y R. Lewontin (1985), "The Organism as the Subject and Object of Evolution”, en Levins R. y R. Lewontin, The Dialectical Biologist, Cambridge, MA: Harvard University Press, pp. 85-106.

Lewontin, R. (1978), “Adaptation”, Scientific American 239: 212-219. 
Lewontin, R. (2000), The Triple Helix: Gene, Organism and Environment, Massachusetts: Harvard University Press.

Marx, C. (2005[1867]), El Capital, Tomo I, Vol. 1, México: Siglo XXI.

Millá, R., Osborne, C.P., Turcotte, M.M. y C. Violle (2015), "Plant Domestication Through an Ecological Lens", Trends in Ecology and Evolution 30: 463-469.

Murphy, D.J. (2007), People, Plants and Genes, Oxford: Oxford University Press.

O’Brien, M. y K.N. Laland (2012), “Genes, Culture and Agriculture: An Example of Human Niche Construction”, Current Anthropology 53: 434-470.

Odling-Smee, J., Laland, K.N. y M. Feldman (2003), Niche Construction: The Neglected Process in Evolution, Princeton, NJ: Princeton University Press.

Richerson, P.J., Boyd, R. y R.L. Bettinger (2001), "Was Agriculture Impossible During Pleistoscene but Mandatory During Holocene? A Climate Change Hypothesis", American Antiquity 66: 387-411.

Sánchez Vázquez, A. (2003), Filosofía de la praxis, México: Siglo XXI.

Schultz, E. (2015), "La construcción de nichos y el estudio de los cambios de cultura en antropología: desafíos y perspectivas", Revista Interdisciplina 3: 131-151.

Smith, B. (2007), "Niche Construction and the Behavioral Context of Plant and Animal Domestication", Evolutionary Anthropology 16: 188-199.

Smith, B. (2011), "General Patterns of Niche Construction and the Management of 'Wild' Plant and Animal Resources by Small-Scale Pre-Industrial Societies”, Philosophical Transactions of the Royal Society B 366: 836-848.

Shomoura, A., Izawa, T., Ebana, K., Ebitani, T., Kanegae, H., Konishi, S. y M. Yano (2008), "Deletion in a Gene Associated with Grain Size Increased Yields During Rice Domestication”, Nature Genetics 40: 1023-1028.

Tester, M. y P. Langridge (2010), "Breeding Technologies to Increase Crop Production in a Changing World", Science 327: 818-822.

Vavilov, N. ([1926] 2009), "Centers of Origin of Cultivated Plants", en Vavilov, N., Origin and Geography of Cultivated Plants, Cambridge: Cambridge University Press, pp. 22-135.

Zeder, M. (2009), “The Neolithic Macro-(R)evolution: Macroevolutionary Theory and the Study of Culture Change”, Journal of Archaeological Research 17: 1-63.

Zohary, D. (2004), "Unconscious Selection and the Evolution of Domesticated Plants”, Economic Botany 58: 5-10. 